\title{
Article \\ Combating COVID-19 during Airway Management: Validation of a Protection Tent for Containing Aerosols and Droplets
}

\author{
Chen-Hsun Weng ${ }^{1}\left(\mathbb{D}\right.$, Po-Wei Chiu ${ }^{2}$, Chia-Lung Kao ${ }^{2}$, Yu-Yuan Lin ${ }^{2}\left(\mathbb{D}\right.$ and Chih-Hao Lin ${ }^{2, *}$ \\ 1 Medical Device Innovation Center, National Cheng Kung University, Tainan 70403, Taiwan; \\ b88501113@gmail.com \\ 2 Department of Emergency Medicine, National Cheng Kung University Hospital, College of Medicine, \\ National Cheng Kung University, Tainan 70403, Taiwan; wayne741002@gmail.com (P.-W.C.); \\ kc18901089@gmail.com (C.-L.K.); yuyuan1122@hotmail.com (Y.-Y.L.) \\ * Correspondence: emergency.lin@gmail.com; Tel.: +886-62353535 (ext. 2237)
}

Citation: Weng, C.-H.; Chiu, P.-W.;

Kao, C.-L.; Lin, Y.-Y.; Lin, C.-H.

Combating COVID-19 during Airway

Management: Validation of a

Protection Tent for Containing

Aerosols and Droplets. Appl. Sci.

2021, 11, 7245. https://doi.org/

10.3390/app11167245

Academic Editor: Min-Suk Bae

Received: 2 July 2021

Accepted: 3 August 2021

Published: 6 August 2021

Publisher's Note: MDPI stays neutral with regard to jurisdictional claims in published maps and institutional affiliations.

Copyright: (C) 2021 by the authors Licensee MDPI, Basel, Switzerland. This article is an open access article distributed under the terms and conditions of the Creative Commons Attribution (CC BY) license (https:// creativecommons.org/licenses/by/ $4.0 /)$

\begin{abstract}
The COVID-19 pandemic has made it necessary for medical personnel to protect themselves from aerosol-producing procedures, especially during airway management. The tracheal intubation process has a significant risk based on the spreading of aerosol, especially when the medical service provider is very close to the airway of the patient. We have developed a novel conservation tent that provides a barrier for healthcare professionals and patients. Through a simulation study, the relationship between the use of the protection tent during intubation and the contamination of medical personnel before and after the movement of the protection tent was explored. A series of experiments in this article provide a theoretical basis for the verification of spray morphology during gas curing and droplet intubation. This inexpensive and simple method for using transparent cloth in the intubation of patients with unknown COVID-19 status can be applied by frontline medical personnel as an additional precautionary measure.
\end{abstract}

Keywords: aerosol; protection tent; intubation; COVID-19; airway

\section{Introduction}

SARS-CoV-2 continues to pose a significant risk of infection and mortality among medical personnel [1-3]. The World Health Organization (WHO) and the International Council of Nurses have reported that thousands of medical personnel have had COVID-19 and hundreds have died because of that $[4,5]$. Risks of infection could occur during the medical treatment of COVID-19 patients. Medical personnel who perform aerosolgenerating procedures are at particular risk [6-8].

Aerosol-generating procedures may expose healthcare professionals to pathogens causing respiratory infections [6-8]. Procedures that generate aerosols and droplets include endotracheal intubation, airway suction, positive pressure ventilation, tracheostomy, chest physiotherapy, nebulizer treatment, sputum induction and bronchoscopy [7-9]. Current guidance for the management of patients with COVID-19 infection suggests that a negative airflow room is preferrable during aerosol nebulization treatment $[9,10]$.

For the most serious patients and those receiving long-term mechanical ventilation, medical personnel use personal protective equipment (PPE) to protect themselves from aerosols from patients with suspected COVID-19 and contaminated surfaces [11-13]. PPE can include goggles, masks, aprons, gowns, clothing, gloves and respirators. PPE is uncomfortable to wear. PPE must be installed properly, and medical personnel may contaminate themselves when they dismantle it [14].

Innovative devices, such as the "Aerosol Box", have been introduced for tracheal intubation [15-18]. While we appreciate these recommendations for protecting medical personnel, these barriers still have limitations when handling patients with COVID-19. Droplets of various sizes can be generated due to a patient coughing during an airway 
intervention. Although PPE may prevent the large droplets resting on the physician's face or body surface, the smaller droplets ( $<5 \mu \mathrm{m}$, i.e., "aerosols") will be delayed, floating inside the barrier device.

The risk of infection from recovered COVID-19 patients should also be considered. With the continual recovery of confirmed COVID-19 patients, a new task arises in determining the timing of emergency treatment for this kind of patient. Studies have shown that the duration of viral shedding is 20 days and can extend to 37 days [19]. Four recovered COVID-19 patients (with absence of clinical symptoms) who conformed to the criteria for hospital discharge or discontinuation of quarantine had positive test results 5 to 13 days later, indicating that a proportion of recovered COVID-19 patients may still be shedding virus [20]. For emergent events where intubation should advance regardless, patients should be supposed to still be infectious; hence, the protection tent could also play a role in risk stratification [21].

We recently developed a protection tent that could potentially reduce the infection risk during airway management [18]. The aim of this study was to validate the protection tent in containing aerosols and droplets.

\section{Materials and Methods}

\subsection{The Protection Tent}

In this work, we have developed a tent that medical staff can use to provide protection, especially when performing intubation on patients with COVID-19. This tent-like device was inspired by an umbrella and a raincoat. The device was made of two L-shaped frames and a transparent polyvinyl chloride membrane. These thin film materials were relatively inexpensive. The schematic design of the protection tent is shown in Figure 1.

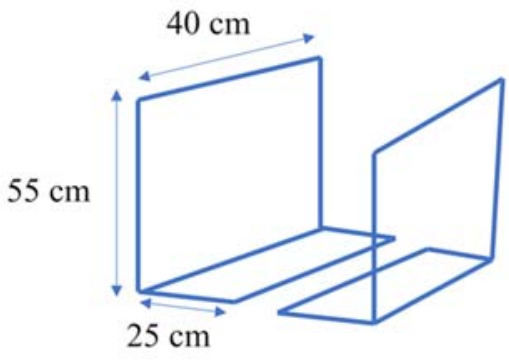

(a) frames

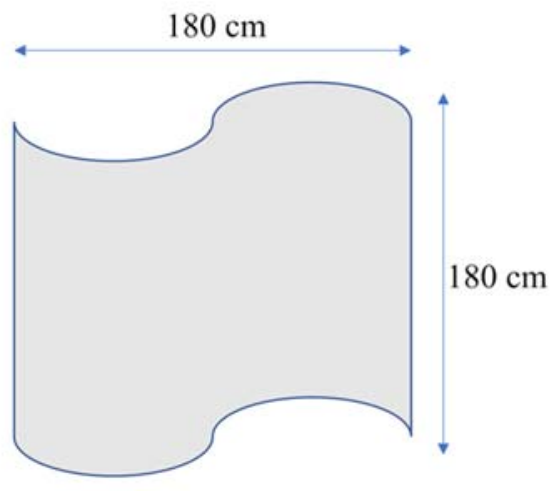

(b) PVC film

Figure 1. The schematic design of the protection tent.

\subsection{Laboratory Setting}

In order to ensure high-quality performance, the laboratory must meet certain requirements, such as performing validation studies on authorized available tests, the use of internal quality controls, and involvement in external quality assessment plans (EQA). Since the WHO and the Innovative New Diagnostic Foundation started organizing to deal with the pandemic, only reference materials and EQA recommendations for SARS-CoV2-based molecular detection have become available to date [22]. To obtain fast, sensitive, highly specific and reliable results about the presence of specific viruses, the quantitative real time polymerase chain reaction (RT-qPCR) is the method of choice.

The AccuPlex ${ }^{\mathrm{TM}}$ SARS-CoV-2 Reference Materials Kit (SeraCare, Milford, MA, USA) was used as the test kit for viral aerosols [23]. This positive reference material contains recombinant virus particles composed of the SARS-CoV-2 genome sequence, including the E gene, RdRp (RNA polymerase dependent on RNA), ORF1a gene and N gene. In addition, the positive references have high similarity with the SARS-CoV-2 virus, which results in the advantages of more realistic virus detection and lower measurement uncertainty. 
The Reference Materials Kit has been approved by the US FDA (U.S. Food and Drug Administration) and is compliant with federal regulations and laboratory standard quality control procedures.

The external control used the AccuPlex ${ }^{\mathrm{TM}}$ SARS-CoV-2 Reference Material Kit and the Reliance One-Step Multiplex Supermix (Bio-Rad Laboratories, Hercules, CA, USA). External positive controls were handled like patient samples to check the RNA extraction, reverse transcription, and RT-qPCR amplification and detection. The supposed outcome was obtained with the external positive control, along with performing positive (template) and negative (non-template) RT-qPCR controls, to clarify the results obtained from patient samples. Primers and probes were synthesized by Tri-I Biotech, New Taipei City, Taiwan. Viral extraction was performed using a Quick-RNA Viral Kit (Zymo Research, Irvine, CA, USA). Two hundred microliters of the sample of the AccuPlex ${ }^{\mathrm{TM}}$ SARS-CoV-2 Reference Material Kit was added to the column and eluted in $15 \mu \mathrm{L}$ of DNase/RNase-Free water, provided in the kit.

The SuperScript ${ }^{\mathrm{TM}}$ III Platinum ${ }^{\mathrm{TM}}$ Taq Mix (Thermo Fisher Scientific, Waltham, MA, USA) was applied for the RT-qPCR with specific primers and probes tagged with FAM. The final concentration of the primers in the reaction was $200 \mathrm{nM}$ in a $50 \mu \mathrm{L}$ reaction. The final concentration of the probe was $100 \mathrm{nM}$. The primers and probes described by the WHO for the diagnostic detection of the SARS-CoV-2 virus by RT-qPCR are shown in Table 1. Thermal cycling was performed at $50^{\circ} \mathrm{C}$ for $15 \mathrm{~min}$ for reverse transcription, followed by $95^{\circ} \mathrm{C}$ for $2 \mathrm{~min}$ and then 40 cycles of $95^{\circ} \mathrm{C}$ for $15 \mathrm{~s}$ and $60^{\circ} \mathrm{C}$ for $30 \mathrm{~s}$. Table 2 shows the setup for the RT-qPCR for the 2019 novel coronavirus.

Table 1. Primer and probe sequences.

\begin{tabular}{ccc}
\hline Primers & Sequence $\left(5^{\prime}-3^{\prime}\right)$ & Annealing Temperature \\
\hline E_Sarbeco_F1 & 5'-ACAGGTACGTTAATAGTTAATAGCGT-3' $^{\prime}$-ATATTGCAGCAGTACGCACACA-3' & \\
E_Sarbeco_R2 & $5^{\prime}$-ATATCA $\mathrm{C}$ \\
E_Sarbeco_P1 & 5'-ACACTAGCCATCCTTACTGCGCTTCG-3 $^{\prime}$ & \\
\hline
\end{tabular}

Table 2. RT-qPCR setup.

\begin{tabular}{cccc}
\hline Process & Temperature & Time & Cycles \\
\hline RT & $50^{\circ} \mathrm{C}$ & $15 \mathrm{~min}$ & 1 \\
Polymerase activation & $95^{\circ} \mathrm{C}$ & $2 \mathrm{~min}$ & \multirow{2}{*}{40} \\
\hline \multirow{2}{*}{$\mathrm{PCR}$} & $95^{\circ} \mathrm{C}$ & $15 \mathrm{~s}$ & \\
& $60^{\circ} \mathrm{C}$ & $30 \mathrm{~s}$ & \\
\hline
\end{tabular}

\subsection{Experimental Setup}

A schematic figure of the experimental setup is shown in Figure 2. A commercial aerosol generator (model ATM228, Topas GmbH, Dresden, Germany) was used to generate positive reference material at $800 \mathrm{hPa}$ and sodium chloride $(\mathrm{NaCl})$ aerosol particles from a $5 \mathrm{wt} \%$ solution prepared in deionized water. The $\mathrm{NaCl}$ droplets were dried by using a silica dryer. Infectious aerosols are suspensions of small organisms in the form of particles in the air. The size of the particle is the most important decisive factor for aerosol behavior. Particles that are $2 \mu \mathrm{m}$ or smaller in size can remain airborne in most indoor environments unless there is removal by air filtration.

Two groups of 10 collectors (MF-Millipore ${ }^{\mathrm{TM}}$ Membrane Filter VSWP02500, Merck, Darmstadt, Germany) were set up with/without protection tents. Each collector performed three intubation simulations with no protection tent and three with a protection tent. In all the tests, the L-shaped frames that were originally placed were not moved. An easy, highly efficient, and sensitive method for the monitoring of airborne pathogenic microorganisms and viruses is the mixed cellulose ester membrane filter method [24]. The suitability of water-soluble filters, especially for virus sampling, has already been tested and proven. These filters are particularly suitable because they show excellent virus collection efficiency 
with high retention rates. As soon as the filter has been dissolved in deionized water, or any other appropriate buffer or medium, all the viral particles retained on the filter can be further processed and detected using RT-qPCR.
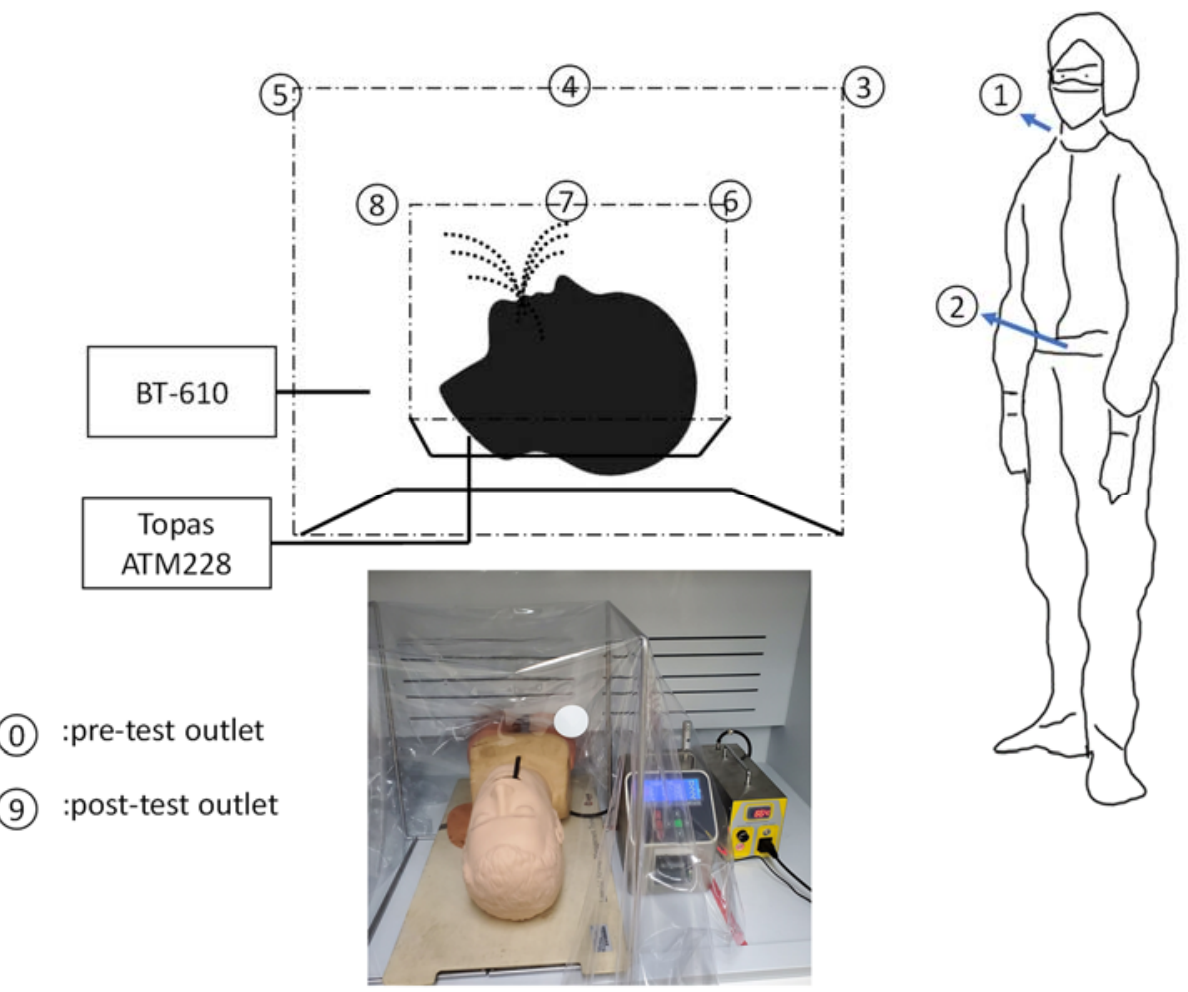

Figure 2. The experimental set up. Numbers $0 \sim 10$ are the collection locations.

Even sensitive RNA material can be detected by a combination of gelatin filtration and RT-qPCR. However, it should be considered that RNA extraction is a crucial step within sample preparation. Therefore, to reduce the loss of genetic material, attention should be given to this step. Several studies have shown that RT-qPCR analysis after air sampling using filters provides recovery results superior to those obtained with other detection methods and hence can be considered a precise and practicable method for the detection of airborne viruses $[25,26]$.

With the recognition that the procedures for generated aerosol are of particular importance to practice in situations with a high risk of infection, an additional tool for intubation training that helped in focusing knowledge and motivating changes to practice in hospitals to use the protective tent was tested. The Glo Germ ${ }^{\mathrm{TM}}$ (Marlatek Inc., Brockville, ON, Canada) was used as the UV fluorescent solution in these simulations, which is 5 10 microns in size. A simulated study was conducted to explore the relationship between protective tent usage during intubation and contamination by medical personnel pre-doffing and post-doffing PPE. This study tested video laryngoscope-assisted intubation on an intubation mannequin with and without a protection tent in a random order.

\subsection{Image Processing}

ImageJ (U. S. National Institutes of Health, Bethesda, MD, USA) was used for particle analysis. The images were cropped to include only the segment to be analyzed [27]. A rolling ball radius of 5 pixels was used to subtract the background algorithmically, with separated colors, and the sliding paraboloid method was used to modify background reflected light and surface reflection. Following this, the function of color adjustment was presented to eliminate red and blue hues. The image was modified for consistency issues and nonparticulate edges, which were then removed manually. The image was converted to an 8-bit image and a binary black and white pixel threshold was applied to the analysis. 


\section{Results}

The overall contamination results of the two L-shaped frames and the medical personnel were the main outcomes, shown in Table 3. There were considerably more areas of contamination noticed on the two L-shaped frames and the PPE of the medical personnel without the aerosol box. The RT-qPCR results show the contamination of 10 locations: Nos. 0 and 9 were the outlets of commercial aerosol generators, and Nos. 1 and 2 were the locations of the medical personnel. Nos. 2-8 were on the two L-shaped frames. These locations are shown in Figure 2. The cleaning effect of the L-shaped frames were tested by using rubbing alcohol, which is often used to clean wounds and surgical instruments. The study results showed that the cleaning effect with disinfection was sufficient for reuse.

Table 3. The RT-qPCR results under different conditions (positive case/total test times).

\begin{tabular}{ccccc}
\hline Location No. & With Tent & Without Tent & $\begin{array}{c}\text { With Disinfection } \\
\text { (after Testing) }\end{array}$ & $\begin{array}{c}\text { Without Disinfection } \\
\text { (after Testing) }\end{array}$ \\
\hline 0 & $3 / 3$ & $3 / 3$ & Not calculated & Not calculated \\
1 & $0 / 3$ & $3 / 3$ & $0 / 3$ & $2 / 3$ \\
2 & $0 / 3$ & $3 / 3$ & $0 / 3$ & $1 / 3$ \\
3 & $0 / 3$ & $3 / 3$ & $0 / 3$ & $2 / 3$ \\
4 & $0 / 3$ & $3 / 3$ & $0 / 3$ & $3 / 3$ \\
5 & $0 / 3$ & $3 / 3$ & $0 / 3$ & $1 / 3$ \\
6 & $0 / 3$ & $3 / 3$ & $0 / 3$ & $2 / 3$ \\
7 & $0 / 3$ & $3 / 3$ & $0 / 3$ & $0 / 3$ \\
8 & $0 / 3$ & $3 / 3$ & $0 / 3$ & $1 / 3$ \\
9 & $3 / 3$ & $3 / 3$ & Not calculated & Not calculated \\
\hline
\end{tabular}

Studies concerning speech-generated and breathing aerosols from patients with various respiratory infections have shown significant similarities in the size distributions of aerosols, with a majority of the organism in small particles $(<5 \mu \mathrm{m})$. These are immediately adapted for respiration, suggesting the need for intubation protection for medical personnel in proximity to potentially infected patients. Positive reference material was generated in the tent for $6 \mathrm{~min}$. The particle numbers in the tent were measured, and particles of different sizes were detected, as shown in Figure 3. The smaller particles were found to be still in the air until the 15th minute and then gradually disappeared. However, when the tent was removed at the 16th minute, the number of smaller particles gradually increased.

The contamination process was simulated with an aerosol generator. The study results showed that using the protection tent could decrease contaminations over the front and back body regions of medical personnel pre-doffing and post-doffing PPE. The protection tent is useful for containing the droplets, as shown in Figure 4a,b, showing that without the protection tent, fluorescent powder could be found in the neck regions when the medical personnel only wore a medical mask. The floor still had fluorescent powder after putting away the tent, as demonstrated in Figure 4c. The observed region was $1.5 \mathrm{~m}$ away from the tent. Before putting away the tent, the observed region did not show the fluorescent powder (image not shown). Finally, the measurement was repeated five times to calculate the fluorescent percent area using ImageJ.

Particle analysis was used with a particle size of 0-infinity and a circularity of 0.0-1.0, with particle counting and percent area calculation, as shown in Figure $4 \mathrm{~d}$. The calculated percent area was $0.58 \% \pm 0.06 \%$. The protection tent may prevent the secretions splashing and decreased the dispersion of aerosolized particles during the intubation procedure. However, medical personnel may still be exposed during the post-intubation period, especially when the protection tent is removed. 


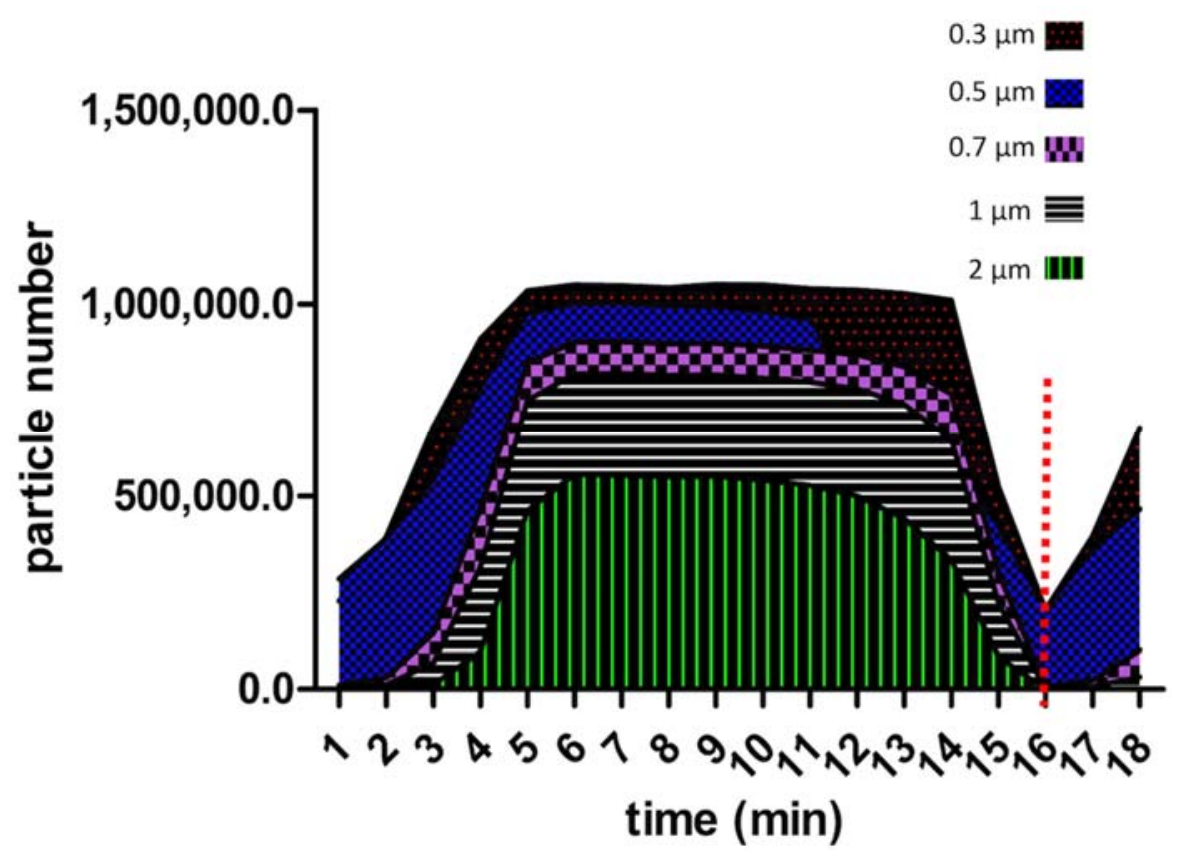

Figure 3. The particle number by time in the tent.

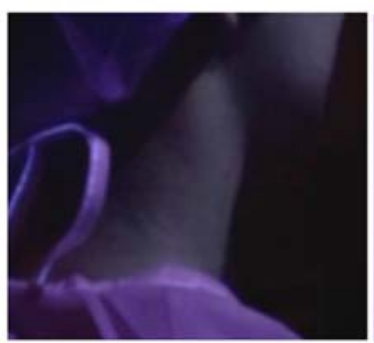

(a)

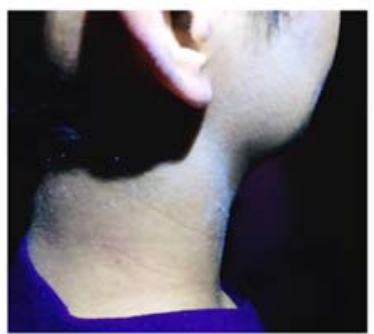

(b)

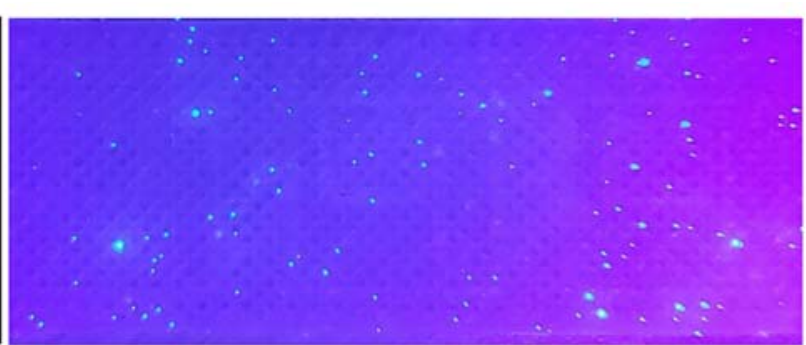

(c)

(d)

Figure 4. Using the protection tent could decrease contaminations over the front and back body regions of medical personnel pre-doffing and post-doffing personal protective equipment. Photos of medical personnel with (a) and without (b) use of the tent were provided. (c) A photo of the fluorescent particles on the floor was obtained. (d) ImageJ was used to analyze the fluorescent particles.

\section{Discussion}

Although mechanisms of COVID-19 infection and treatment have been proposed and investigated [28,29], the concept of using physical barriers to reduce infection risks still plays an important role in clinical practices [30,31]. PPE with various types and levels are available to provide certain protection for medical personnel from infectious diseases [31-33]. However, wearing PPE is generally cumbersome and may interfere with technical performance, especially during life-saving procedures. Performing endotracheal intubation for patients with COVID-19 carries a high risk for medical personnel. The 
current SARS-CoV-2 pandemic poses significant challenges for front-line medical personnel, especially those working in the emergency department. They often engage in treatment with insufficient information about the patients.

Filter half-masks for respiratory protection are subject to various regulatory standards worldwide $[1,7,8]$. These standards specify certain required physical properties and performance characteristics for respirators to comply with a particular standard or norm [34]. However, the medical masks mainly serve to prevent the spread of small particles from their users to the environment. The medical masks prevent the penetration of microorganisms from the inside out and thus primarily protect the surroundings (infected or potentially infected) of the user, although the N95 respiratory mask filters particles and microorganisms more efficiently. The data of the maximum permissible resistance for inhalation, the minimum filtering protection efficiency and the respirator filtering capacity must be qualified using a standard. However, unknown patients should be supposed to still be infectious; hence, the protection tent could also play a role in risk stratification, and healthcare professionals must wear a medical mask or N95 respiratory mask.

In order to manage the current COVID-19 outbreak, extensive measures need to be taken to lower the person-to-person transmission of the virus. In addition to this, special efforts and attention are required to reduce or protect susceptible populations, such as elderly people, health care providers and children. More studies are also essential to understand the mechanisms related to COVID-19 pathogenesis. This better understanding will help the development of specific and effective therapies against SARS-CoV-2. Since the respiratory tract is mainly affected by SARS-CoV-2, special consideration is required to deliver drugs into the respiratory tract.

To reduce the exposure of medical personnel to SARS-CoV-2 via airborne aerosols, a potential solution is portable tents that not only create barriers between medical persons and patients during airway management, but also utilize negative pressure with HEPA filtration. The bench tests in simulated hospital environments could provide significant support for the function of several recently developed devices and localized negative pressure systems. Prior to and during clinical use of the tent, the patient's body temperature and $\mathrm{CO}_{2}$ and oxygen levels should be monitored. Infection control measures might not only reduce the probability of infection but might also reduce the size of the droplets/aerosols. However, the aerosol eventually evaporates, and the final particle may have a relatively high charge. Humidity creates a bridge between a particle and a surface. The effect of evaporation decreases in the case of high air humidity, so smaller aerosols will still be present in the form of fine droplets for a certain period. Moving the tent might also result in an increase in droplet diameter and spread efficiency.

A major limitation of our protection tent is that before removing the tent from the patient, medical personnel should wait at least $20 \mathrm{~min}$ after performing airway management or aerosol-generating procedures. This 20-min waiting period helps to ensure that aerosols have been cleared prior to opening the tent. We hope the 20-min waiting period can be reduced to $5 \mathrm{~min}$ by improving our design.

\section{Conclusions}

Our series of experiments were a proof of concept of the patterns of aerosolization and droplet sprays during intubation. The use of the protection tent was able to create a barrier and limit aerosolization and droplet spray. The inexpensive and simple method of using clear drapes during the intubation of patients with an unknown COVID-19 status may be considered by front-line medical personnel as an additional precaution. Modifications of the plastic tent can be adapted for surgical procedures or during ambulance transfer.

\section{Patents}

The tent used in this study was granted a patent by the Intellectual Property Office, Ministry of Economic Affairs, Taiwan (A Protection Tent for Airway Management in Patients, M598615). 
Author Contributions: Conceptualization, C.-H.W. and C.-H.L.; methodology, C.-H.W.; software, C.-H.W. and P.-W.C.; validation, C.-H.W. and C.-H.L.; formal analysis, C.-H.W.; investigation, C.-H.W., C.-H.W., Y.-Y.L. and C.-H.L.; resources, C.-H.W., C.-L.K. and C.-H.L.; data curation, C.-H.W.; writing-original draft preparation, C.-H.W. and C.-H.L.; writing-review and editing, all authors; visualization, C.-H.W., P.-W.C. and C.-H.L.; supervision, C.-H.L.; project administration, C.-H.L.; funding acquisition, C.-H.W. and C.-H.L. All authors have read and agreed to the published version of the manuscript.

Funding: This study was supported by the Taiwan Ministry of Science and Technology (MOST 109-2327-B-006-008 and MOST 109-2327-B-006-005).

Institutional Review Board Statement: The study protocol fulfilled the requirement for a waiver of Institutional Review Board of the National Cheng Kung University Hospital, Tainan, Taiwan.

Informed Consent Statement: Not applicable.

Data Availability Statement: Data can be made available on request from established research groups with an appropriate data-sharing agreement. Please contact the corresponding author for data sharing.

Acknowledgments: We appreciate the devotion of Pin-Hui Fang and the support of the Medical Device Innovation Center (MDIC) and National Cheng Kung University (NCKU) from the Featured Areas Research Center Program within the framework of the Higher Education Sprout Project by the Ministry of Education (MoE) in Taiwan.

Conflicts of Interest: The authors declare no conflict of interest. The funders had no role in the design of the study; in the collection, analyses, or interpretation of data; in the writing of the manuscript; or in the decision to publish the results.

\section{References}

1. Taylor, R.S.; Pitzer, M.; Goldman, G.; Czysz, A.; Simunich, T.; Ashurst, J. Comparison of intubation devices in level C personal protective equipment: A cadaveric study. Am. J. Emerg. Med. 2018, 36, 922-925. [CrossRef]

2. $\quad$ El-Boghdadly, K.; Wong, D.J.N.; Owen, R.; Neuman, M.D.; Pocock, S.; Carlisle, J.B.; Johnstone, C.; Andruszkiewicz, P.; Baker, P.A.; Biccard, B.M. Risks to medical personnel following tracheal intubation of patients with COVID-19: A prospective international multicentre cohort study. Anaesthesia 2020, 75, 1437-1447. [CrossRef]

3. Flaishon, R.; Sotman, A.; Ben-Abraham, R.; Rudick, V.; Varssano, D.; Weinbroum, A.A. Antichemical protective gear prolongs time to successful airway management: A randomized, crossover study in humans. Anesthesiology 2004, 100, 260-266. [CrossRef] [PubMed]

4. Mekonen, E.; Shetie, B.; Muluneh, N. The Psychological Impact of COVID-19 Outbreak on Nurses Working in the Northwest of Amhara Regional State Referral Hospitals, Northwest Ethiopia. Psychol. Res. Behav. Manag. 2020, 13, 1353-1364. [CrossRef] [PubMed]

5. World Health Organization. State of the World's Nursing: Investing in Education, Jobs and Leadership; WHO: Geneva, Switzerland, 2020; Available online: https://www.who.int/publications-detail/nursing-report-2020 (accessed on 1 December 2020).

6. Leung, N.H.L.; Chu, D.K.W.; Shiu, E.Y.C. Respiratory virus shedding in exhaled breath and efficacy of face masks. Nat. Med. 2020, 26, 676-680. [CrossRef] [PubMed]

7. Tran, K.; Cimon, K.; Severn, M.; Pessoa-Silva, C.L.; Conly, J. Aerosol generating procedures and risk of transmission of acute respiratory infections to medical personnel: A systematic review. PLoS ONE 2012, 7, e35797. [CrossRef] [PubMed]

8. Jackson, T.; Deibert, D.; Wyatt, G.; Durand-Moreau, Q.; Adisesh, A.; Khunti, K.; Khunti, S.; Smith, S.; Chan, X.H.S.; Ross, L. Classification of aerosol-generating procedures: A rapid systematic review. BMJ Open Respir. Res. 2020, 7, e000730. [CrossRef] [PubMed]

9. Kaur, R.; Weiss, T.T.; Perez, A.; Fink, J.B.; Chen, R.; Luo, F.; Liang, Z.; Mirza, S.; Li, J. Practical strategies to reduce nosocomial transmission to healthcare professionals providing respiratory care to patients with COVID-19. Crit. Care 2020, 24, 571. [CrossRef]

10. Bin Nafisah, S.A.; Mzahim, B.Y.; Aleid, B.S.; Sheerah, S.A.; Almatrafi, D.Q.; Ciottone, G.R.; AlAnazi, K.H.; Khan, A.A. The risk of coronavirus to healthcare providers during aerosol-generating procedures: A systematic review and meta-analysis. Ann. Thorac. Med. 2021, 16, 165-171. [CrossRef] [PubMed]

11. Shin, D.H.; Choi, P.C.; Na, J.U.; Cho, J.H.; Han, S.K. Utility of the Pentax-AWS in performing tracheal intubation while wearing chemical, biological, radiation and nuclear personal protective equipment: A randomised crossover trial using a manikin. Emerg. Med. J. 2013, 30, 527-531. [CrossRef]

12. Greenland, K.B.; Tsui, D.; Goodyear, P.; Irwin, M.G. Personal protection equipment for biological hazards: Does it affect tracheal intubation performance? Resuscitation 2007, 74, 119-126. [CrossRef] 
13. Aljahany, M.; Alassaf, W.; Alibrahim, A.A.; Kentab, O.; Alotaibi, A.; Alresseeni, A.; Algarni, A.; Algaeed, H.A.; Aljaber, M.I.; Alruwaili, B. Use of In Situ Simulation to Improve Emergency Department Readiness for the COVID-19 Pandemic. Prehosp. Disaster Med. 2021, 36, 6-13. [CrossRef]

14. Verbeek, J.H.; Rajamaki, B.; Ijaz, S.; Sauni, R.; Toomey, E.; Blackwood, B.; Tikka, C.; Ruotsalainen, J.H.; Kilinc Balci, F.S. Personal protective equipment for preventing highly infectious diseases due to exposure to contaminated body fluids in healthcare staff. Cochrane Database Syst. Rev. 2020, 4, CD011621. [CrossRef]

15. Maniar, A.; Jagannathan, B. The aerosol box. J. Anaesthesiol. Clin. Pharmacol. 2020, 36, S141-S143. [CrossRef] [PubMed]

16. Azhar, M.N.; Bustam, A.; Poh, K.; Zahedi, A.Z.A.; Nazri, M.Z.A.M.; Ariffin, M.A.A.; Md Yusuf, M.H.; Zambri, A.; Chong, J.Y.O.; Kamarudin, A.; et al. COVID-19 aerosol box as protection from droplet and aerosol contaminations in medical personnel performing airway intubation: A randomised cross-over simulation study. Emerg. Med. J. 2020, 38, 111-117. [CrossRef] [PubMed]

17. Choi, J.; Shin, T.G.; Park, J.E.; Lee, G.T.; Kim, Y.M.; Lee, S.A.; Kim, S.; Hwang, N.Y.; Hwang, S.Y. Impact of Personal Protective Equipment on the First-Pass Success of Endotracheal Intubation in the ED: A Propensity-Score-Matching Analysis. J. Clin. Med. 2021, 10, 1060. [CrossRef] [PubMed]

18. Fang, P.H.; Lin, Y.Y.; Lin, C.H. A protection tent for airway management in patients with COVID-19 infection. Ann. Emerg. Med. 2020, 75, 787-788. [CrossRef] [PubMed]

19. Yang, B.; Fan, J.; Huang, J. Clinical and molecular characteristics of COVID-19 patients with persistent SARS-CoV-2 infection. Nat. Commun. 2021, 12, 3501. [CrossRef] [PubMed]

20. Shui, T.J.; Li, C.; Liu, H.B. Characteristics of recovered COVID-19 patients with recurrent positive RT-PCR findings in Wuhan, China: A retrospective study. BMC Infect. Dis. 2020, 20, 749. [CrossRef] [PubMed]

21. Lui, R.N.; Wong, S.H.; Sánchez-Luna, S.A.; Pellino, G.; Bollipo, S.; Wong, M.Y.; Chiu, P.W.Y.; Sung, J.J.Y. Overview of guidance for endoscopy during the coronavirus disease 2019 pandemic. J. Gastroenterol. Hepatol. 2020, 35, 749-759. [CrossRef]

22. Matheeussen, V.; Corman, V.M.; Mantke, O.D. International external quality assessment for SARS-CoV-2 molecular detection and survey on clinical laboratory preparedness during the COVID-19 pandemic, April/May 2020. Eurosurveillance 2020, 25, 2001223. [CrossRef]

23. Arumugam, A.; Faron, M.L.; Yu, P.; Markham, C.; Wu, M.; Wong, S. A Rapid SARS-CoV-2 RT-PCR Assay for Low Resource Settings. Diagnostics 2020, 10, 739. [CrossRef]

24. Song, H.; Crawford, I.; Lloyd, J.R.; Robinson, C.H.; Boothman, C.; Bower, K.; Gallagher, M.; Allen, G.; Topping, D. Airborne Bacterial and Eukaryotic Community Structure across the United Kingdom Revealed by High-Throughput Sequencing. Atmosphere 2020, 11, 802. [CrossRef]

25. Verreault, D.; Moineau, S.; Duchaine, C. Methods for sampling of airborne viruses. Microbiol. Mol. Biol. Rev. 2008, 72, 413-444. [CrossRef] [PubMed]

26. Borges, J.T.; Nakada, L.Y.K.; Maniero, M.G. SARS-CoV-2: A systematic review of indoor air sampling for virus detection. Environ. Sci. Pollut. Res. 2021, 1-14. [CrossRef]

27. Chen, J.X.; Workman, A.D.; Chari, D.A. Demonstration and Mitigation of Aerosol and Particle Dispersion During Mastoidectomy Relevant to the COVID-19 Era. Otol. Neurotol. 2020, 41, 1230-1239. [CrossRef]

28. Behl, T.; Kaur, I.; Bungau, S.; Kumar, A.; Uddin, M.S.; Kumar, C.; Pal, G.; Shrivastava, K.S.; Zengin, G.; Arora, S. The dual impact of ACE2 in COVID-19 and ironical actions in geriatrics and pediatrics with possible therapeutic solutions. Life Sci. 2020, 257, 118075. [CrossRef]

29. Kabir, M.T.; Uddin, M.S.; Hossain, M.F.; Abdulhakim, J.A.; Alam, M.A.; Ashraf, G.M.; Bungau, S.G.; Bin-Jumah, M.N.; AbdelDaim, M.M.; Aleya, L. nCOVID-19 Pandemic: From Molecular Pathogenesis to Potential Investigational Therapeutics. Front. Cell Dev. Biol. 2020, 8, 616. [CrossRef] [PubMed]

30. Hsieh, C.C.; Lin, C.H.; Wang, W.Y.C.; Pauleen, D.J.; Chen, J.V. The Outcome and Implications of Public Precautionary Measures in Taiwan-Declining Respiratory Disease Cases in the COVID-19 Pandemic. Int. J. Environ. Res. Public Health 2020, $17,4877$. [CrossRef]

31. Kao, C.L.; Lin, C.H. A Novel Mask to Prevent Aerosol Spread during Nebulization Treatment. J. Formos. Med. Assoc. 2021, 120, 769-771. [CrossRef]

32. Givi, B.; Schiff, B.A.; Chinn, S.B. Safety recommendations for evaluation and surgery of the head and neck during the COVID-19 pandemic. JAMA Otolaryngol. Head Neck Surg. 2020, 146, 579-584. [CrossRef] [PubMed]

33. Matava, C.T.; Yu, J.; Denning, S. Clear plastic drapes may be effective at limiting aerosolization and droplet spray during extubation: Implications for COVID-19. Can. J. Anaesth. 2020, 67, 902-904. [CrossRef] [PubMed]

34. Otrisal, P.; Bungau, C.; Obsel, V.; Melicharik, Z.; Tont, G. Selected Respiratory Protective Devices: Respirators and Significance of Some Markings. Sustainability 2021, 13, 4988. [CrossRef] 